\title{
LA DIPLOMACIA DE CARLOS III EN ITALIA (*)
}

\author{
Rafael OLAECHEA
}

Universidad de Zaragoza

Voy a desarrollar el tema de "La diplomacia de Carlos III en Italia" dividiendo su exposición en dos partes. En la primera haré algunas observaciones introductorias -indispensables- en torno a la diplomacia española como instrumento pragmático de la Política Exterior de Carlos III; y en la segunda destacaré algunos rasgos concretos de dicha diplomacia, específicamente inherentes a la llamada "Política Italiana" del tercer Borbón español.

\section{I}

Es evidente que la Política Exterior de cualquier país civilizado (y en concreto la de España en el siglo XVIII) se hallaba determinada y condicionada tanto por los imperativos e incentivos de su propia geo-política, como por las presiones y exigencias derivadas, simultáneamente, de las geo-políticas de otras naciones más o menos limítrofes.

Este postulado me da pie para decir, con otras palabras, que: dejando a un lado la dimensión americana (que aquí no nos incumbe), toda la Política Exterior de Carlos III en el ámbito europeo estuvo marcada inesquivablemente por el hierro de las cláusulas de dos Tratados Internacionales: el de Aquisgrán (1748, y el de París (1763).

Aunque el primero de ellos pertenece al reinado de Fernando VI (1746-59), produjo sin embargo dos tipos de efectos: unos inmediatos, y otros más remotos. Por un lado, delimitó, sobre el suelo italiano, las fronteras de la ambiciosa "política familiar" (quiero decir: de la empleomanía casera) de la reina Isabel de Farnesio, segunda esposa del primer Borbón español Felipe V (1700-46). Y por otro, polarizó las motivaciones - futuras- de la Política Exterior de Carlos III directamente vinculadas con la Península Italiana.

Tal es así, que puede afirmarse, sin exageración, que salvo una excepción, el gobierno de Carlos III no hizo, con respecto a Italia, más que seguir, adaptándolas a las

(*) Texto de la conferencia que el autor pronunció el 2 de diciembre de 1988 en la Escuela Diplomática de Madrid. 
exigencias del momento, las líneas maestras trazadas por el Marqués de la Ensenada en el magno Informe (tan luminosamente analizado por el hispanista francés Didier Ozanam), que el riojano dirigió a Fernando VI en 1751.

¿Y cuál fue tal excepción. Pues, simplemente, el no haber adoptado como Norte invariable, una máxima que don Cenón solía repetir con frecuencia: "Con Francia paz, pero no amistad, ni alianza". Y así le fue -como le fue- a la Política Exterior de Carlos III (y naturalmente a España) por no haber seguido dicho principio a rajatabla.

El mismo conde de Floridablanca, omnipotente ministro de Estado (1776-1792), reconocería dolido, que el Tercer Pacto de Familia (1761), tan descabelladamente gestionado por su antecesor ministerial, el Marqués de Grimaldi, constituyó " un paso desafortunado" ( $¡$ y ya es eufemismo!), que condujo a España a una guerra ruinosa, cuyos resultados abocaron en "el vergonzoso Tratado de París de 1763".

Lo más deplorable del caso es: que Floridablanca, por una mal entendida fidelidad personal a su protector Grimaldi, no menos que al obcecado "borbonismo" de Carlos III, se mantuvo uncido "malgré lui" a la política "francófila" del genovés, y cerró los ojos ante una infinidad de vejaciones inferidas a España por el país vecino, que siempre trató despóticamente a nuestra nación, y jamás la consideró como a una aliada parigual, sino como a una entidad subalterna de menor cuantía política.

No es, pues, extraño que ante las consecuencias derivadas del Tercer Pacto de Familia (que permaneció vigente hasta 1793), hiciera el conde de Aranda el siguiente comentario: "Siempre he tenido a los ingleses como a nuestros mayores y más precisos enemigos, por razón de intereses; y a los franceses, como a nuestros peores amigos, a pesar de la estrechez de sangre que reina entre las Cortes de Madrid y Versalles". Comentario que aclara desde otro ángulo la opinión popular: de que el elemento que aglutinaba las "relaciones" de España con Francia en el siglo XVIII no era precisamente la "franco-filia", sino su ancestral "anglo-fobia".

Con estas pinceladas he pretendido esbozar, sumariamente, las coordenadas internacionales que encuadraban la proyección de la Política Exterior de Carlos III sobre el plano europeo; Política Exterior, cuyos intereses específicos con respecto a la Península Italiana, tenían unos antecedentes político-religiosos pluriseculares.

Baste recordar, sobre este particular, la presencia catalano-aragonesa en las Dos Sicilias (donde, por cierto, surgieron, antes que en Flandes, los primeros brotes difamatorios de un capítulo de "la leyenda negra" antiespañola). En segundo lugar, los Virreinatos de Nápoles y Milán (para no hablar de Cerdeña), creados y gobernados, con todas sus secuelas, por los Austrias españoles. Y finalmente, que el hecho de ser España un país católico "de iure", hacía que su comunicación con la bifronte Corte de Roma fuera, según veremos, tan continua como copiosa.

Ahora bien, la Política Exterior de España se servía de un instrumento fundamental para ir realizando sus proyectos en el área internacional. Esta herramienta material era la Diplomacia, que constituía un Cuerpo -el Diplomático-, cuyos miembros (embajadores, ministros plenipotenciarios, encargados de negocios, secretarios) dependían directamente del Ministro o Secretario de Estado, que en el siglo XVIII tenía a su cargo la gerencia de la Política Exterior hispana.

Esto significa, en rigor, que resulta menos exacto (o más inexacto) referirse, en general, a la Diplomacia de Carlos III, que a la de sus dos ministros de Estado -el Marqués de Grimaldi y el Conde de Floridablanca- que cubrieron todo el tiempo de su 
reinado (1759-1788). Cierto que el monarca era el último responsable de éste, y de los demás sectores de gobierno de la nación; pero no es menos cierto que fueron Grimaldi, y sobre todo Floridablanca, quienes regularon en cuanto pudieron -es decir, mediocremente- el funcionamiento del Cuerpo Diplomático Español, pues ellos eligieron (a dedo, claro está) a los componentes de dicha Institución, y les asignaron sus respectivos destinos y puestos de acción.

Todavía más superfluo que "llevar lechuzas a Atenas" -glauk'eis Athenassería, como se deja entender, que yo osara decir, aquí y ahora, algo original o nuevo no ya sobre "La Diplomacia", como género político transaccional, pero aun sobre la marca de fábrica o el estilo peculiar de "La Diplomacia de España en el siglo XVIII". Sólo para no pasar por un provinciano indocumentado, pero no sin cierto rubor profesional, me permito citar la obra de P. R. Rohden (Die klassische Diplomatie von Kaunitz bis Metternich), y el librito de H. Nicholson (La Diplomacia, FCE México), que es, a mi juicio, una síntesis de la sabiduría del propio autor, diplomático y a la vez historiador de talla, pero cuya vida privada sólo puede ser descrita en una lengua muerta. En ambas obras se describe, desde distintos puntos de vista, lo que era la Diplomacia clásica en el siglo XVIII europeo.

Orillando, pues, muchos e interesantes matices propios del multímodo y variopinto mundo -a veces titirimundo- de "la"' Diplomacia (con D mayúscula) y, reduciéndonos al meollo de la cuestión, juzgo que lo importante en esta ocasión es formular, sintéticamente, lo que era más esencial en el quehacer cotidiano de cualquier diplomático (español o europeo) del siglo XVIII, cuyas funciones se reducían, en suma, a estos tres complejos capítulos:

1. Representar en un país extranjero a su propia nación, procurando dar la mejor imagen de ésta.

2. Negociar (ventajosamente) con el Gobierno de dicho país extranjero asuntos de tipo político, comercial-económico, técnico, cultural e incluso turístico.

3. Informar puntual y detalladamente a su propio Gobierno cómo iban las cosas por el país en cuya Corte se hallaba ejerciendo las funciones de embajador.

Como no tengo fibra de político, y por mis venas tampoco corre, que yo sepa, ni una gota de sangre fenicia (pues soy nulo para el regateo), únicamente aludiré, como aprendiz de historiador, al valor documental de los Informes y Despachos oficiales que los embajadores (y algunos cónsules) enviaban a sus respectivos Gobiernos. Sus correspondencias constituyen una caudalosa fuente de datos, cuyo volumen ha sido altamente beneficioso para la investigación histórica.

Hace algún tiempo, el prestigioso historiador don Vicente Palacio Atard nos dio (como suele y nos tiene acostumbrados) una magnífica lección sobre la importancia y los límites -"servitude et grandeur- de las correspondencias diplomáticas como fuentes documentales de valor histórico, en el Prólogo a los trece volúmenes de Berichte de los embajadores austríacos en España durante el reinado de Carlos III, que podemos manejar cómodamente gracias al tesón del benemérito hispanista alemán, profesor Hans Juretschke.

Una de las experiencias que he sacado de la lectura de las correspondencias diplomáticas de algunos embajadores extranjeros acreditados en el Madrid de Carlos III es: la modernidad de contenido que ofrecen los despachos oficiales de los representantes de los-digamos- "países menores", en comparación con los plasmados por los 
embajadores de las grandes potencias europeas. La razón básica de esta diferencia radica, a mi juicio, en que los embajadores de las grandes potencias (incluidos los Nuncios de la Corte de Roma), al informar a sus respectivos gobiernos, solían dar en general un énfasis preferente a los acontecimientos político-ministeriales de España, al paso que concedían un margen de atención más restringido al sector económico-social.

Por el contrario, los embajadores de las naciones sin pretensiones imperialistas -tales como los de Dinamarca, Génova, Venecia, Suecia o los Países Bajos-, enfocaban las relaciones de sus respectivos países con España desde el ángulo exclusivamente comercial. De ahí que insistieran en sus despachos e informes, de una manera preferente, sobre este último aspecto, o sobre la posibilidad, conveniencia -y garantías- de poder hacer inversiones rentables en fábricas e instalaciones industriales, no menos que sobre la oportunidad de obtener del Gobierno español patentes para el transporte de cereales, o monopolios en exclusiva, para el suministro de pescado, dejando en un segundo término los cambios "político-ministeriales", e interesándose por ellos en la medida en que tales incidencias pudieran afectar a la economía y al comercio de sus respectivos países.

Todo esto hace que la correspondencia diplomática de los embajadores de las naciones menores tenga, para nuestra sensibilidad histórica actual, un interés de nuevo cuño. Ello es fácilmente explicable, ya que hasta fechas relativamente recientes la historiografía hispana tenía más en cuenta las correspondencias diplomáticas de los embajadores de las grandes potencias, que las de los representantes de segundo orden, debido sin duda alguna a que, hasta hace poco tiempo, la Historia meramente política primaba en España sobre la económico-social.

Para ser un buen diplomático era condición indispensable poseer, ante todo, el hábito o el instinto de saber captar en su misma fuente el poder del Gobierno ante el cual se estaba acreditado; en segundo lugar, el asegurarse la confianza del monarca y del ministro de Estado del país de destino; y finalmente, el informar a su propio Gobierno del resultado de sus gestiones y observaciones, sin adelantarse a los acontecimientos, pero sabiéndolos prever, con arreglo al viejo y sabio consejo del festina lente.

Claro está que, dentro de estas líneas generales, cada diplomático actuaba según su propia idiosincrasia, al hilo de las circunstancias que, según el país donde se hallara, se le ofrecían cada día; y aquí es donde se ponía a prueba la ingeniatura de cada embajador. Pero la sutileza de su pensamiento, y la finura de su olfato político (y en esto jugaba mucho la valía personal de cada uno) eran las cualidades que daban de ordinario eficacia a su gestión diplomática.

Los informes, cartas confidenciales y despachos oficiales que enviaban los embajadores españoles del XVIII (que eran, por lo demás, los hombres de confianza de Madrid, destacados en el extranjero), constituían una de las mejores fuentes de información del ministro de Estado español, ya que ellos, los embajadores, eran quienes plasmaban la "idea política" que el Gobierno hispano se iba formando de los Gabinetes europeos. No en vano dijo el ministro inglés Palmerston, que "las opiniones gubernamentales eran más poderosas que los ejércitos". Lo triste, lo español -quiero decir: lo chapucero del caso- es (la investigación histórica lo está revelando cada vez con más claridad): que en Madrid se hacía en general muy poco caso de tales informes (que a veces eran piezas maestras de sagacidad y observación), y que tanto el indolente 
Marqués de Grimaldi (Aranda lo calificaba de "holgazán"), así el archiazacanado Conde de Floridablanca, archivaban tales informes, dándoles el "visto bueno", y contentándose con restañar malamente las cuestiones más pungentes, y salir del paso de la misma manera.

Sé que me pongo un cepo (por lo peliagudo de la respuesta), si me pregunto a mí mismo: a ver si los embajadores de Carlos III en Europa, y concretamente en la Península Italiana se atuvieron a las que el citado H. Nicholson llamó "las reglas del arte de la diplomacia". Pero a poco honrado que se sea -y también se trata de eso--, debo hacerme esa pregunta, y responder en cuanto yo creo saber: que sin querer justificar la actuación deficiente de no pocos diplomáticos españoles del siglo XVIII, son muy explicables algunos de sus despistes y deslices, a causa de los ayunos de pautas e instrucciones que les tenía - por culpa o sin culpa de los correos- el ministerio de Madrid.

Por ésta y otras razones, no pocos de ellos vivían tan prevenidos $-\mathrm{y}$ atemorizados- ante la idea de que sus informes y representaciones pudieran ser descalificados, o de caer en desgracia por haber comprometido la Política Exterior de España, que preferían no actuar y dedicarse a la holganza, o hinchar sus despachos con el relato de insignificantes minucias, haciendo como que hacían, pero dejando escapar las mejores ocasiones para negociar ventajosamente en favor de su patria.

Después de este "excursus" introductorio pasemos a la segunda parte de la exposición, en la que trataré, propiamente, de la diplomacia de Carlos III en Italia, en cuanto la Diplomacia era -como ya dije- el hilo instrumental conductor de la "política italiana" del monarca cazador.

Y partamos de un hecho objetivo y claro: que las relaciones entre la España de Carlos III y los distintos Reinos de la Península Italiana eran, en el siglo XVIII, asaz caudalosas. Y ello por varias razones:

- En primer lugar, porque entonces vivía en Italia un elevado número de españoles, vasallos del rey (diplomáticos, artistas, clérigos, religiosos, estudiantes, artesanos, funcionarios, comerciantes, militares, curiales, agentes, criados y sirvientes), cuya abigarrada tipología abarcaba una gama muy pintoresca.

- En segundo lugar, porque España y sus católicos habitantes estaban, como ya insinué al principio, en continua comunicación con la Corte de Roma; más tarde veremos las razones y causas de este comercio.

- En tercer lugar, porque Carlos III tenía una relación de paternidad con su hijo Fernando IV, rey de las Dos Sicilias, y un estrecho parentesco de sangre con su hermano Felipe, Duque de Parma. Considerablemente más flojos eran sus lazos con la Toscana, donde sin embargo vivía su hija María Luisa, casada en 1765 con el Gran Duque Leopoldo, vástago del tronco austríaco, en cuanto que era hijo de la prolífica emperatriz María Teresa de Habsburgo.

Ciñéndonos únicamente a la faceta diplomática, cuanto acabo de decir queda avalado por el hecho de que en el ministerio de Estado de Madrid, existía entonces una sección especial, que llevaba el significativo título de Negociado de Italia, que enten- 
día y atendía privativamente los asuntos concernientes a las relaciones entre España y aquella Península, y para cuyo desempeño y desenvolvimiento estaban destinados varios covachuelistas, con sus respectivas mesas, a las órdenes directas del ministro de Estado, que era al mismo tiempo de Asuntos Exteriores.

Por otro lado, poseemos una especie de prontuario, que nos permite conocer las directrices teóricas (otra cosa era la realidad práctica cotidiana) de la llamada "política italiana" de Carlos III. Me refiero a la famosa Instrucción Reservada, que Floridablanca confió a la Junta de Estado en julio de 1789, esto es, año y medio después del fallecimiento de Carlos III.

En esta Instrucción aparece clara la nervadura de la política italiana de España, que presenta dos vertientes bien diferenciadas. Una de ellas se proyectaba sobre los países italianos regidos por príncipes de la rama borbónica, como eran Nápoles y Parma; y la otra englobaba a los demás Estados italianos, incluidos -en primer término- los Pontificios.

Basta una lectura no demasiado atenta del documento de Floridablanca, para percatarse de que este ministro, además de establecer la referida división de vertientes (que ocupa once artículos), aplicaba a Saboya, Génova, Toscana, Venecia o Roma, unos criterios políticos diferentes que a Nápoles y Parma, países de "familia".

Al margen de esta discriminación, todos los Estados italianos merecían, a juicio de Floridablanca, "la protección y los auxilios de España", no sólo porque así lo exigía la dinámica geo-política del Tercer Pacto de Familia, sino para frenar el insaciable apetito de poder, y moderar las ambiciosas injerencias (sea por las armas o más larvadamente por medio de una política matrimonial) de la Corte de Viena.

Hechas estas observaciones orientadoras, detengámonos brevemente en cada uno de los Estados italianos, empezando por los que no eran de "familia", y dejando para el final las relaciones de España con Parma, Roma y las Dos Sicilias.

1. Pocos quebraderos ocasionó a España el Reino de Saboya, en cuya capital, Turín, vivía una hermana de Carlos III, esposa del rey sardo Carlos Manuel Víctor III (173073), y madre de su sucesor en el trono Víctor Amadeo II (1773-96). Dicho en jerga diplomática, Turín era entonces una tranquila - por no decir aburrida - embajada de tránsito, y el ministerio de Estado español la utilizó en ocasiones, para aparcar en ella a embajadores achacosos (como el Conde de Aguilar, o el Vizconde de la Herrería), cuando no para alejar de España a algún sujeto influyente de la oposición, como ocurrió con el Duque de Villahermosa, miembro del "partido aragonés", y émulo político de Floridablanca.

No le fue, pues, muy dificultoso a Carlos III mantener con Saboya unas relaciones continuadas de buena amistad, confianza y armonía. Entre otras razones, ello se debió en mucha parte a que el caudal de tales relaciones era tan exiguo, y su aforo tan tenue, que su falta de contenido repercutía en la vacuidad de los despachos oficiales que los embajadores españoles enviaban desde allí a Madrid.

Sin presumir de nada (si no es de paciente), me permito asegurar que hace falta ser benedictino, o un "enragé" de la Historia, para tragarse, legajo tras legajo, la prosa insípida de estos buenos diplomáticos hispanos, que no tenían cosa de fuste con que informar a Madrid, como no fuera el paso de algún viajero ilustre por Turín, o algún lío de faldas aristocráticas y alto coturno. 
2. En la República de Génova, con su gran puerto, vio siempre España una de las principales puertas de penetración en Italia; pero como Madrid no tenía entonces la más mínima pretensión invasora, mantuvo siempre con la Serenissima Signoria Genovesa unas relaciones de amistad y confianza, que favorecieron no poco el comercio entre ambos países.

A la recíproca, Génova tuvo siempre en Madrid un embajador acreditado, y Raffaele Ciasca publicó en Roma, el año 1968, las "Istruzioni e Relazioni" de dichos diplomáticos genoveses desde 1745 a 1797.

Carlos III estuvo representado en Génova, durante todo su reinado, por dos hombres. Uno de ellos fue el longevo ministro Juan Cornejo, que llegó a Génova en 1737, y se jubiló reinando ya Carlos IV (1789-1808). El otro fue el cónsul José Uriondo, un bilbaíno que inició sus funciones en 1761, y murió en su puesto consular en 1798.

Uriondo fue uno de los cónsules españoles que, sin estar obligado a ello, informaba sin embargo por su cuenta al Gobierno de Madrid, y reiteraba con frecuencia las noticias enviadas a España con anterioridad por Cornejo, mejor informado que él, " $\mathrm{ex}$ ratione officii", de los asuntos políticos europeos. Nos consta además que ambos sujetos se llevaban bien, pero como Cornejo escribía con una letra muy grande, con cuatro renglones de tinta ocre (la estoy viendo) llenaba un folio, de modo que sus despachos eran siempre de lo más voluminoso por el número de sus páginas.

Uno de los asuntos de mayor monta, en que Cornejo y Uriondo intervinieron de consuno, fue el referente al desembarco en el puerto genovés de varios miles de jesuitas españoles y americanos, procedentes de la isla de Córcega, donde Francia (y no España, como se ha venido diciendo erróneamente) los había confinado provisionalmente al ser expulsados por Carlos III de todos sus dominios el año 1767.

Los testimonios de dichos religiosos (al menos los que yo he leído), coinciden en afirmar lo bien tratados y atendidos que fueron por uno y otro en lo posible, cuando pasaron por allí de camino para establecerse en los Estados Pontificios.

3. Como las miras de la Corte vienesa eran reunir el Gran Ducado de Toscana a los Estados hereditarios de la casa de Austria, España trataba a Toscana, en el siglo XVIII, con el mismo distanciamiento y frialdad diplomática que a Austria, de manera que si se ha hablado - y con razón- de cierta " austrofobia" de Carlos III, lo propio cabría decir de su "toscanofobia".

Por eso es tan significativo que dos de los sujetos que el ministro Floridablanca destinó a Florencia, capital y Corte del Gran Ducado, con el rango inferior de ministros representantes, y no de embajadores, fueran: don Francisco Moñino, mejor conocido por $\mathrm{PaCO}$, hermano del mismísimo Floridablanca, y después a don Francisco Salinas Moñino, hijo de una hermana de aquél, que había actuado antes como legado suyo en Marruecos, según nos cuenta V. Rodríguez Casado en su libro sobre la "Política marroquí de Carlos III" (Madrid, 1946).

Fuera de que con esta "combinazione" todo quedaba en la cocina familiar, excuso el decir que estos dos sujetos, superprotegidos desde arriba, no estaban en situación de atreverse a rechistar cuando el tieso Floridablanca les ordenaba comunicar al Gran Duque Leopoldo alguna representación más protocolaria que política, y se entiende que así fuera, porque tanto "el inaplicado Paco" como el sobrino Salinas, 
además de meros correveidiles, eran unos peleles políticamente mudos, aunque -eso sí- cargados de honores, collares y entorchados.

Pero el Gran Ducado de Toscana, además de una Corte, poseía en la costa tirrena el magnífico puerto natural de Livorno, que participaba de lleno en el poderoso ritmo de las rutas comerciales mediterráneas, como señalan Carrière y Courdurie en su documentado estudio sobre "Las grandes horas de Livorno en el siglo XVIII".

En esta ciudad liberal y libertina tenía España un Consulado, para asuntos de tipo comercial, que desde 1717 estaba regentado por los Silva, una familia napolitana de origen portugués, a la que pertenecían dos Duarte de Silva, marqués de Banditella, y su aventurero hijo Manuel que, después de zascandilear por algunas Cortes europeas (incluida la rusa), heredó el título nobiliario, y en 1771 ocupó el Consulado español, al frente del cual permaneció, con mucho menos prestigio que su padre, hasta el año 1803.

4. Cuando Floridablanca decía en la "Instrucción Reservada" que a la República de Venecia le convenía vivir en "amistad y confianza recíproca" con España, ello era porque, en el siglo XVIII, la neutral y decadente Serenísima Señoría de Venecia había dejado de ser "chisme del mundo, azogue de los príncipes y cerebro de Europa" (como la definió nuestro Quevedo), para convertirse en la capital del ocio europeo, y en el asilo lujoso de los visitantes desocupados.

Por otro lado, como el comercio seguía siendo para ella cuestión de vida o muerte, se había resignado a aceptar -como otrora los Fenicios-el papel de "transportista marítima", y no le iba mal con este recurso, de suerte que España se servía con frecuencia de las naves venecianas, para que transportaran cereales y otras mercancías y vituallas a los puertos hispanos del Mediterráneo. El "Mercurio histórico y político", periódico gubernamental que salía a la luz cada mes, señala a este respecto que, en los años 1776 y 1777 , entraron 28 embarcaciones venecianas en los cinco puertos españoles más importantes de las costas cantábricas y mediterráneas.

Con esto se sobreentiende que las relaciones hispano-venecianas eran, en el siglo XVIII, primordialmente comerciales, y por lo mismo no hay por qué dar importancia ni relieve a la cuestión de las franquicias, y otras cominerías protocolarias que se terciaban de cuando en cuando entre el Senado veneciano y la secretaría de Estado de Madrid, como conté más extensamente en un libro que publiqué hace algunos años con el título de "Un embajador veneciano en la España de Carlos III: Alvisio Mocenigo (1762-68)'. (Madrid, CSIC, 1978).

El primer representante que tuvo Carlos III en Venecia fue José Joaquín Guzmán de Montealegre (1698-1771), marqués del mismo nombre, y desde 1740 Duque de Salas. Nació en Sevilla, y muy joven aún trabajó en la Secretaría de Estado en Madrid durante el reinado de Felipe V. Agregado al séquito del infante don Carlos -futuro Carlos III-, pasó con él a Parma y después a Nápoles, donde ejerció el cargo de ministro de Estado para asuntos exteriores, y tuvo a su cargo la dirección de la Casa Real. Después de la caída de Manuel Benavides de Aragón, Conde de Santisteban (1738), cogió las riendas del gobierno napolitano hasta 1748, año en que fue destituido. Vuelto a España en 1759, fue nombrado mayordomo mayor de la reina María Amalia, y en diciembre de 1760 del propio rey Carlos III, que le envió como embajador a la República de Venecia, donde terminó sus días en junio de 1771. 
Ahora bien, una cosa es que este caballero, al morir, dejara sus cuentas hechas un pandemonium, que no sólo puso a prueba la paciencia del fiel secretario Isidoro Martín para arreglarlas, sino que provocó un clamoroso pleito interpuesto por una "cortigiana" de trapío, a la que el vejete y panzudo marqués había puesto un "meublé garni", y ahora reclamaba ella su parte en calidad de "coima onorata"; esto -como digo- es una cosa, y otra muy distinta que los informes y despachos oficiales enviados por Montealegre año tras año a Madrid son tan plúmbeos, que se le caen a uno de las manos, pues por sus líneas no corre ni una brizna de aire que alivie la lectura.

En julio de 1772, le sucedió en la embajada el célebre Marqués de Esquilache -el del motín de Madrid--, y su nombramiento se debió al compadrazgo rehabilitador del Marqués de Grimaldi, que sabía ser fiel a lo amigos, sobre todo si eran "macarroni", y por contra víctimas de la xenofobia hispana, como lo sería él mismo a raíz del desastre de la expedición de Argel (1775). Tampoco es una temeridad pensar que en este nombramiento anduvo de por medio la paternidad (no el paternalismo) de Carlos III. No seré yo -iDios me libre!- quien tire el menor guijarro al tejado del ilibado y continente monarca, viudo ejemplarísimo, ni quien ponga la menor tilde a la virtud conyugal de doña Pastora, la esposa del Marqués de Esquilache, porque de eso se encargaron, entre otros, el historiador A. Ferrer del Río, el novelista francés Stendhal, y el propio cardenal De Gregorio, hijo putativo de los Marqueses de Esquilache, el cual, insinuando en el cónclave de 1823 que su calidad de hijo natural de Carlos III era un mérito para ser elegido Papa, decía: "Je suis un Bourbon... quoiqu'on en disse".

Al morir Esquilache en 1785, le sucedió en el cargo el donostiarra Simón de las Casas, cuñado del "General Fracaso"' (como llamaba el pueblo al general don Alejandro O'Reilly), y protegido de Floridablanca, que en 1781 le nombró embajador de España en Berlín, donde tuvo ocasión de tratar al gran Federico II de Prusia. El aragonés José Nicolás de Azara, compañero suyo de covachuela, decía socarronamente que "el sol no calentaba mayor camueso" que Casas, el cual llegó a la embajada de Venecia en mayo de 1786, huyendo de las iracundas solfataras de la reina de Nápoles, donde su misión diplomática constituyó, como veremos, el más rotundo fracaso.

5. El Ducado de Parma fue el nicho familiar en que la reina Isabel de Farnesio colocó a su segundo hijo Felipe, como sucesor de su hermano mayor Carlos, que desde 1734 reinaba en Nápoles con el nombre de "don Carlos".

Parma se le antojaba a Felipe un agujero indigno de él (que no era ninguna lumbrera), y aunque vivió muchos años rodeado de españoles conspicuos (baste citar, entre otros, al Marqués de la Ensenada, para no hablar de Muzquiz y Muniáin, futuros ministros de Carlos III), su matrimonio con la infanta Luisa Isabel, hija del rey Luis XIV, "afrancesó", por así decirlo, la minúscula corte parmesana.

La influyente Luisa Isabel consiguió llevar a Parma al "ilustrado" bayonés Du Tillot, Marqués de Felino, al que puso al frente de las finanzas; y al filósofo sensista Condillac lo nombró preceptor de sus hijos Fernando y María Luisa, que en 1765 se casaría en Madrid con el hijo de Carlos III, el príncipe de Asturias, futuro Carlos IV. Sin hacer el menor caso a las patrañas del erotómano Marqués de Vila-Urrutia, las crónicas del tiempo y el inmortal cuadro de Goya titulado "La familia de Carlos IV" suministran suficientes datos para formarnos una leve idea de la catadura moral y física de la reina María Luisa, protectora del impresentable favorito Manuel Godoy. 
En 1765 murió el infante Felipe, y le sucedió su apocado hijo Fernando. Su matrimonio con la archiduquesa austriaca María Amalia (hermana de María Antonieta, esposa de Luis XVI, y de María Carolina, reina de Nápoles), que se celebró a disgusto de su tío Carlos III, puso a éste en guardia, tanto frente a las posibles injerencias de Austria que, con su política matrimonial -'Tu, Austria felix, nube'--, podía desviar al ducado parmesano de las órbitas del Tercer Pacto de Familia, como ante la persona misma de la archiduquesa María Amalia, mujer de genio caprichoso, y viciosamente adicta al juego, en el que despilfarraba verdaderas fortunas. De hecho, Fernando y María Amalia nunca se entendieron bien, y terminaron separándose, viviendo muchos años cada uno por su lado.

A todo esto, el ministro Du Tillot seguía adelante con sus reformas internas, que conducían a un enfrentamiento cada vez mayor con la Curia Romana. Su política desamortizadora, alentada desde Madrid por el regalista don Manuel de Roda, ministro de Gracia y Justicia (1765-1782), y por el propio Carlos III, abocó en el ruidoso Monitorio (enero 1768), por el que el Papa Clemente XIII excomulgó al infante Felipe y a sus colaboradores más inmediatos. Esta decisión pontificia produjo un enorme escándalo y conmoción en las Cortes Borbónicas.

Parma respondió suprimiendo la Inquisición, y expulsando del Ducado a los jesuitas, de cuyas temporalidades se apoderó acto seguido. En Madrid, los fiscales Moñino y Campomanes lanzaron el "Juicio Imparcial" (refutación del Monitorio de Parma), que hubo de ser retirado de la circulación por su rusiente regalismo, sin que su expurgo le librara de ser incluido en el Indice de libros prohibidos, y Carlos III envió a Parma, como representante suyo, para que sostuviera al Duque contra los embajadores romanescos, al covachuelista José Agustín de Llana, oficial mayor muy protegido de Grimaldi.

Por una serie de circunstancias que no vienen al caso, porque su análisis nos llevaría muy lejos, el manipulado infante Fernando sacó arrestos de no sabemos dónde, para "cambiar de casaca", y como consecuencia de esta mutación, Du Tillot fue depuesto y expulsado del Ducado "in continenti", quedando escorada su obra reformista.

Ante esta arriscada reacción, Carlos III retiró de Parma a Llano, y las relaciones hispano-parmesanas quedaron interrumpidas, hasta que don José Moñino, a la sazón embajador de España en Roma, consiguió que el Papa Clemente XIV le concediera el "gambito" de revocar el Monitorio, y levantar la excomunión al Duque, a condición de que él morigerara sus acosos, y le concediera tiempo para ir difiriendo la decisión de suprimir la Compañía de Jesús, paso que el Papa daría en julio de 1773.

Sólo entonces volvió Llano a la legación de Parma, y en adelante discurrieron, como "El Don apacible", las relaciones entre el dócil Duque y su tío Carlos III que, dejando a un lado sus carraspeos y reservas, envió a Parma como sucesor de Llano al "ilustrado" aragonés Fernando Magallón, antiguo cavachuelista, secretario de embajada en París, y personaje de solera, que moriría en Parma el año 1785.

6. Hace años publiqué una obra en dos tomos sobre "Las relaciones hispano-romanas en la segunda mitad del siglo XVIII, la Agencia de Preces" (Zaragoza, 1965), lo que indica que cuanto diga aquí sobre este particular, será necesariamente una síntesis homeopática de lo que allí escribí. 
Por lo mismo, y como punto de partida sólido para la presente ocasión, bueno será establecer la naturaleza del poder de los dos "partenaires" de este alucinante torneo suscitado por el enfrentamiento entre el Sacerdotium y el Imperium.

Por un lado, Carlos III, monarca católico regalista, protector de la Iglesia católica romana, y ejecutor del Concilio de Trento en sus dominios, que no firmó ningún Concordato con la Corte de Roma, pero que, además del Patronato Universal (1753), detentaba desde 1765 el Vicariato Regio de América, fantásticos atributos que le conferían el derecho a presentar (para que el Papa de turno les confirmara canónicamente, previo pago de una tasa establecida por la Santa Sede) a todos los candidatos destinados a ocupar todas las mitras, canonjías, abadías, colegiatas y beneficios eclesiásticos no laicales (con excepción de 53 piezas) de todos sus dominios de España e Indias, en las cuales era un verdadero Vice-Papa, pues en ellas no había Nuncio, ni lo hubo hasta bien entrado el siglo XIX.

Por otro lado, la que los diplomáticos de entonces llamaban con frase técnica: la Corte de Roma, en cuya cima se hallaba el Papa, que era, a un mismo tiempo, soberano de los Estados Pontificios (rodeado de una poderosa e influyente Curia -mezcla de Dicasterio y Ministerio- y asistido por un Cuerpo Diplomático compuesto e integrado por los Nuncios Apostólicos), y vicario de Cristo, es decir, cabeza de todos los fieles católicos, que conservaba y utilizaba para su doble gobierno las "reglas de cancillería", y las "regalías eclesiásticas", correlato antípoda de las regalías mayestáticas de los monarcas católicos.

Esta ambivalencia de poderes en una misma persona daba lugar a abusos, a confusionismos, y, como decía José Nicolás de Azara, agente español en Roma, a un "indecente mercimonio de dispensas, indultos, gracias, privilegios y exenciones".

Pero era en la misma Roma, donde los negocios que allí se ventilaban daban, sin duda alguna, un relieve más acusado al dualismo del poder pontificio. Porque si un monarca católico de Europa -en concreto el rey Carlos III - tenía embajador acreditado en las principales capitales de las naciones europeas -Londres, París, Berlín, Lisboa, Nápoles o San Petersburgo-, en Roma tenía dos delegados: uno era el embajador propiamente dicho, y el otro el agente general de preces.

Los mismos Papas refrendaban con la práctica esta dualidad, y así como recibían a los embajadores con un protocolo y un ceremonial determinados, y trataban con ellos de asuntos más bien políticos (o si eran espirituales, estaban más o menos amalgamados con los políticos); para los agentes generales de preces o peticiones tenían abiertos sus Tribunales y Dicasterios, en los cuales se tramitaban cuatro géneros de negocios de mayor o menor calado espiritual. Tales negocios eran:

1. Los referentes a la provisión de toda la gama de beneficios eclesiásticos (tanto laicales como patronales), cuyo número sobrepasaba las 5.000 piezas, y su tramitación constituía un férvido mundo de economía y de picaresca.

2. Los concernientes a la obtención de licencias matrimoniales, para que pudieran casarse legítimamente -es decir, lícita y válidamente- parejas afectadas por ciertos impedimentos -dirimentes e impedientes- que hoy día son unos pocos, pero entonces eran unos dieciocho en total.

3. Los relativos a la impetración de las preces o peticiones particulares que los católicos españoles elevaban al Papa, y cuyo tenor era variadísimo, porque en ellas lo mismo podría entrar una solicitud para tener un altar portátil, para que un clérigo 
doctor pudiera decir la misa con anillo, para que una religiosa de clausura pudiera salir del convento a tomar baños por prescripción facultativa, o para representar un auto sacramental en el claustro de una catedral o de un monasterio.

En Roma había agentes privados, que conseguían por su cuenta estas gracias paticulares para los españoles, pero a un precio más caro, y al margen del agente real, con gran irritación de éste, y del Gobierno de Madrid, que luchó en vano años y años para suprimir esta corruptela, y canalizar todas las preces por la vía segura - y más barata- del agente general del rey.

Como el pago previo de las tasas señaladas por la Curia Romana era la "conditio sine qua non" para poder impetrar tales preces, no estará de más indicar que, en algunas situaciones críticas, el embajador y el agente se ponían de acuerdo, para desencadenar, por asedio, un ataque en regla contra éste a aquel Dicasterio. Cuando el Papa o su Gobierno se negaban a tratar o ventilar un asunto político con el embajador español, el agente retenía en represalia, sin darles curso, las preces que llegaban cada semana desde España y América. Las arcas pontificias acusaban estiaje, y como los curiales, al ver alcanzados sus bolsillos con la pérdida de corretajes, ponían el grito en el cielo, el Papa, para acallar las protestas, terminaba poniéndose de acuerdo con el embajador.

Ya se entiende que estos incidentes eran como la "facies picaresca" de un problema mucho más vasto y más hondo: un problema de dependencia, y en último término de supremacía y de economía. Por lo mismo, el Gobierno de Carlos III trataba de buscar la manera de cortar el chorro de dinero que iba continuamente de España a Roma, para sufragar el coste de unas gracias que,por ser espirituales, debían -rationabilitar- ser concedidas gratis, y además podían otorgarlas los Obispos españoles sin tantos gastos, sólo con que éstos entraran en posesión de sus "facultades episcopales originarias", que Roma les había quitado "sine die", y se negaba a devolvérselas.

Tal ocurrió en 1778, con un caso de envergadura que quiero mencionar por lo que tiene de relevante. Desde hacía años, Madrid venía reclamando en vano a la Curia de Roma que se hiciera por fin, y de una vez, un arancel fijo de las tasas de todas las preces, de modo que su expedición se redujera a la mano única del agente del rey, y los españoles no fueran esquilmados arbitrariamente, ni cayeran en las garras voraces de los agentes privados.

Como pasaba el tiempo y todo continuaba igual, en Madrid tomaron la desidia por una solemne tomadura de pelo, y Carlos III, por medio del ministro Floridablanca, ordenó al agente de preces Azara, que intimara a la curia: que como no regulara de una forma estable la expedición de las preces, Madrid suspendería el envío de dinero para sufragar - como solía - los costes de las causas de canonización y beatificación de españoles, cuyos procesos solían ser carísimos.

Esta vez la cosa iba en serio, pues el agente Azara escribía en octubre de 1778 a su amigo el ministro Roda: "Ha llegado aquí la orden ministerial para la suspensión de las causas (de canonización) españolas. Hoy envío a la Secretaría de Estado la lista de las que siguen pendientes en la Congregación de Ritos; son cuarenta y tres. Usted sabe los millones que cuesta el sostenerlas, y podrá hacerse idea de lo que nos chupan las lechuzas de este "boteghino", que es el más rico de Roma".

Finalmente, en 1780 estuvo listo el "Plan General de Expediciones" (obra que tantos trabajos y sinsabores costó al diligente Azara), y Madrid volvió a soltar la bolsa 
para sufragar las canonizaciones españolas. Esto no obstante, quiero subrayar por su alcance, que el llamado "Negociado de las Causas" era el cuarto tipo de preces (más arriba mencioné los otros tres), sólo que este asunto no corría por el canal del agente general del rey, sino que se gestionaba oficial y directamente, por vía diplomática, entre Congregación de Ritos y el ministerio de Estado de Madrid, sin la inferencia de ningún otro intermediario, a excepción -como se deja entender- de los "postuladores generales" de dichas causas, que eran nombrados por el monarca español.

Y aquí aparece de rechazo un aspecto - tal vez inadvertido- de cuán cierta era la realidad práctica del tantas veces citado axioma absolutista: "Todo para el pueblo pero sin el pueblo". Todo, absolutamente todo, sin excluir nada. De modo que el monarca gobernaba a sus vasallos en cuerpo y alma; y les prescribía "vellis nolis" no sólo los arbitrios cívicos o medidas higiénicas, sino las devociones que podían practicar, y hasta los santos que debían venerar. Era la Iglesia Católica Nacional y Colonial, con un monarca que regía a sus súbditos para hacerlos "felices" en la tierra, y luego llevarlos al cielo "a la española", a disfrutar de un paraíso aparte, para sólo los españoles.

Don Manuel de Roda (hasta 1765), y después Azara, fueron los dos agentes generales de preces que cubrieron todo el reinado de Carlos III. En cambio hubo varios embajadores suyos en Roma, como también hubo en Madrid unos cuantos Nuncios Apostólicos, que desde la Nunciatura manejaban el Tribunal de la Rota, fuente de pingües dividendos (Azara lo calificaba de "garitera"), y se injerían en asuntos político-religiosos de España, actuando manifiestamente o bajo manga, según conviniera, e informando de todo al cardenal secretario de Estado en Roma.

Carlos III procuró en cuanto pudo tenerlos bienquistos, sin dejar por eso de intervenir su correspondencia diplomática con Roma, y aunque hubo un período de casi cinco años sin nuncio en Madrid, como represalia contra el Monitorio de Parma, es muy revelador el que, salvo Alberico Lucini y Luigi Valenti, todos los demás nuncios con mandato en Madrid aceptaron al marcharse las elevadas pensiones vitalicias, que Carlos III les concedió reservadamente, para que favorecieran los negocios de España, cuando estuvieran establecidos en Roma como cardenales.

Además de agente general de preces, el aragonés Roda fue el primer representante diplomático que Carlos III tuvo en Roma. Regalista convicto y confeso, este personaje apasionado aunque de maneras suaves era temido en Roma "por el odio implacable que nutría contra el Gobierno pontificio", según decía el secretario de Estado cardenal Torrigiani.

En 1765 le sucedió el canónigo zaragozano D. Tomás Azpuru, figurón engolado cuyo principal cometido se redujo en la práctica a estos dos puntos: organizar la instalación y establecimiento en Italia de los jesuitas hispano-americanos extrañados por el monarca cazador, para cuyo objeto fue nombrado "superintendente general". Y en segundo lugar, formar un frente común con los embajadores borbónicos de Nápoles y Francia en Roma, para exigir del Papa la pronta extinción de la Compañía de Jesús, negocio que tanto Carlos III como su confesor Osma (más conocido por "alpargatilla", o el padre Confites) llevaban muy en el corazón, sin necesidad de que les espoleara a ello el ministro francés Choiseul.

Azpuru participó en la destitución del projesuítico cardenal secretario Torrigiani, pero procuró cuanto pudo hurtar el bulto en el engorroso asunto de la supresión de la Compañía de Jesús; más aún, dando apariencias de celo, procuró ayudar secretamente 
al Papa Clemente XIV a que no expidiera el decreto de extinción, o dilatara lo más posible dar este paso.

En Madrid calaron su juego, y decidieron destituirlo, como ocurrió en efecto, con el pretexto de su achacoso estado de salud. Lo triste del caso es Azpuru estaba convencido de que sus ocultos servicios al Papa Ganganelli le granjearían el capelo cardenalicio que, según su testimonio, se lo había prometido el propio pontífice. El desengaño de verse nombrado solamente arzobispo de Valencia, y no cardenal, que era el hipo de su vida, fue tan grande, que el disgusto le produjo la muerte. ¡Tristes servidumbres de algunos altos jerarcas eclesiásticos!

El sucesor de Azpuru en la embajada fue el fiscal D. José Moñino, que llegó a Roma en julio de 1772. En la Instrucción de partida se le encomendaba la negociación de cuatro asuntos, en tres de los cuales salió victorioso:

1. En dar una nueva planta y organización al Tribunal de la Rota en Madrid, punto éste que fue documentalmente estudiado y ejemplarmente expuesto en 1961 por el Dr. Constantino García Martín.

2. En reducir a términos justos y moderados el derecho de asilo, cuya inmunidad causaba en las ciudades de España continuos altercados y discordias entre la autoridad civil y la eclesiástica, como expuse en un trabajo que dediqué en 1966 al estudio de esta cuestión.

3. En conseguir que el Papa Clemente XIV decretara la supresión de la Compañía de Jesús, acto que tuvo lugar el julio de 1773. Esta gestión, que le mereció el título de Conde de Floridablanca, ha sido estudiada y analizada por muchos autores desde distintos puntos de observación. Yo me limito aquí a decir que, a la carta que le escribió el Marqués de Esquilache, desde Venecia, felicitándole calurosamente por haber "conseguido extinguir a los Jenízaros de la Santa Sede"' (como escribía textualmente), Floridablanca le respondió con suma sobriedad manifestando que "la feliz conclusión de tan grave negocio, sólo se debía atribuir a la Providencia del Altísimo, que lo ha querido reservar para mi tiempo". Maravilla el ver lo insondables que son, a veces, la "pietas" y la "humilitas" de algunos hombres públicos, a los que hace grandes el cargo que ocupan y no al revés.

4. El único negocio que Floridablanca no logró resolver favorablemente en Roma fue el referente a la beatificación del venerable obispo Juan de Palafox y Mendoza, asunto polémico que daría lana para más de una velada, pero que necesariamente he de pasar por alto.

Además de esto, aún le quedó tiempo a Moñino para hacer en la ciudad eterna otras cosas, algunas de ellas confesables, y otras no tanto, si bien él mismo no tuvo ningún empacho en airearlas públicamente. A la muerte de Clemente XIV, en septiembre de 1774, Moñino tomó una parte muy eficaz y activa en el carnavalesco cónclave del que salió elegido Papa una "persona grata" para España, que subió al solio pontificio con el nombre de Pío VI (1775-1799). Tan serias ocupaciones no fueron óbice para que se enredara, en un "fatarello amoroso", con Juliana de Falconieri, princesa de Santacroce, dama internacional a la que el murciano hizo un hijo (en diminutivo cariñoso: Checo), ante la vista gorda del consentido marido de ella, quien por tan complacientes servicios fue hecho Grande de España, y premiado con una sustanciosa pensión vitalicia.

Cuando todo el mundo esperaba que el agente Azara sería el sucesor de Florida- 
blanca en la embajada, Carlos III desconcertó a todos colocando en ella al Marqués de Grimaldi, cuya gestión diplomática se redujo a la burocracia, en los cortos espacios que le dejaban sus largas ausencias en Génova y en Venecia, donde era atendido por su amigo el Marqués de Esquilache.

En tales casos le sustituía el avezado Azara, que nunca se entendió con el genovés (sus respectivos genios eran muy distintos, y además se terciaba la xenofobia del aragonés), y cuando en diciembre de 1784 el vivaz agente fue nombrado embajador plenipotenciario, escribió confidencialmente al Conde de Aranda estas líneas lapidarias, dignas -creo- de un "graffito" de Pompeya, aunque no sé si muy propias de un miembro del digno Cuerpo Diplomático: "En fin, Grimaldi consumó su renuncia. Soy su humilde sucesor. Ha costado 50 años a España sacudirse esta ladilla".

Todavía en enero de 1786, Carlos III, ungido por su confesor Osma, volvió a la carga pidiendo la apertura del proceso de beatificación de Palafox, cuya causa había sido condenada a "perpetuo silencio", y aunque Pío VI no se avino a tan peregrina pretensión, no por eso se deterioraron las relaciones hispano-romanas, ya que el papa Braschi tranquilizó al monarca prometiéndole, como cumplió fielmente, que mientras él fuera Papa no restablecería la Compañía de Jesús.

7. Y como colofón, la diplomacia -o mejor dicho, la falta de diplomacia, la terquedad apasionada y la estrechez de miras- de Carlos III en sus relaciones con $e l$ reino de las Dos Sicilias.

También aquí debo advertir -y no es excusa-, que mis comentarios sobre este punto estarán trenzados con hilos sacados de un librito que publiqué en Nápoles en 1985.

Dos ideas brujuleaban en la mente de Carlos III, con respecto a Nápoles, cuando vino de allí en 1759 a ocupar el trono de España. La primera atañía al modo de mantener acoplada la política napolitana a los esquemas del Pacto de familia francoespañol. La segunda se refería a la manera de seguir interviniendo velada, pero eficazmente, desde España en el gobierno interior del reino napolitano, donde había dejado a dos de sus hijos: a su primogénito Felipe, "minorato mentale" de doce años, y, como sucesor suyo, a su tercer hijo Fernando, bajo la férula del omnipotente ministro Bernardo Tanucci.

Pero Tanucci cayó en desgracia en 1776, y su destitución supuso una especie de giro copernicano de la Corte partenopea. Carlo di Gros, agente secreto a sueldo del ministro Roda, le escribía desde Nápoles por aquellos días: "Compadezco al nuevo ministro Sambucca, si no arregla el gran desorden dejado por Tanucci. Se ve al Rey mucho más aplicado que antes a los negocios del Gobierno, y no sólo ha dejado de jugar, sino que ha prohibido el juego en la Corte, lo que evidencia que el mayor interés (de Carlos III por medio de Tanucci) ha sido, hasta ahora, tener distraído al Rey, para que se fuera degradando".

Este buen rey, rutinario y cazador, con estampa de pacífico alcalde de barrio, como nos han pintado a veces a Carlos III, ocultaba sin embargo una ambición desmedida, pues esa misma táctica, de fomentar su vida disoluta y mantenerlo en la degradación, la utilizó con su hermano el infante Luis, para evitar que le sucediera en el trono español, como he puesto de relieve en un trabajo reciente ("Información y acción política". Revista de Investigaciones Históricas, n. 7, Valladolid, 1988), en el que explico las motivaciones de tan faraónico proceder. 
Pese a su vigilancia, y a su empeño en seguir teniendo en sus manos las riendas de Nápoles, Carlos III tampoco dudó en evitar que su hijo Fernando IV, “i1 Nassone', se casara, como el Duque de Parma, con la archiduquesa austriaca María Carolina, mujer de carácter enérgico (Napoleón dijo que era "todo un hombre bien aguerrido"), que logró imponerse a su indolente marido, y aceleró la caída del pedante Tanucci.

Aunque María Carolina no rehusó en absoluto sus deberes conyugales (pues fue madre de 17 hijos entre varones y hembras), se enredó además en amoríos más o menos escabrosos, el último de los cuales fue con el general Acton, un francés cedido a Nápoles por Leopoldo, Gran Duque de Toscana.

Con Acton, que sería nombrado ministro de Marina y de Guerra, y más tarde de Estado, la política napolitana dio un doble viraje. Por un lado, fue buscando ostensiblemente la protección austriaca; y por otro, se hizo patente su inclinación hacia Inglaterra. En cualquier caso, gracias a Acton, los reyes de Nápoles comenzaron a dar pruebas inequívocas de que habían alcanzado la mayoría de edad política, y que no les hacía falta (si alguna vez la habían necesitado) la tutela opresora de España.

Carlos III se fue percatando, sin engaño alguno, de que en la Corte de su hijo Fernando ya no se cumplían, como en los "buenos tiempos de Tanucci", las "sugerencias" de Madrid; y que los mejores puestos de administración y de gobierno del reino napolitano de distribuían entre austriacos y toscanos, excluyéndose de ellos a los españoles. En una palabra, el pertinaz monarca vio con sorpresa y rabia que Nápoles se le escapaba de las manos.

$Y$ en los tercos y obcecados empeños de no consentir que se consumara del todo este "desvío" político-familiar, radica en suma el meollo de las relaciones diplomáticas hispano-napolitanas durante algunos años de la década de los 80 . Lo demás es mero relato anecdótico, cuando no opereta bufa, en cuyas aristas entraba el tieso Floridablanca haciendo una figura ridícula. Porque el conseguir que Nápoles continuara, con respecto a España, como en tiempos de Tanucci, fue el principal, por no decir el único encargo que recibieron los embajadores españoles enviados en vano por Carlos III a la Corte napolitana.

Tal fue el caso de Angel Trigueros, encargado de negocios, que en 1783 recibió la orden de quitar las barreras que impidieran el "reencuentro" entre padre e hijo, de modo que éste se sometiera sumiso, pidiera perdón, y dejara de hacer travesuras más propias de un mozalbete díscolo que de un rey, aunque fuera de paja o de papel. Mal pudo cumplir Trigueros la intimación de Floridablanca, porque además de ir ascendiendo la estrella del favorito Acton, en diciembre de ese mismo año, el emperador austriaco José II (que ya había estado en Nápoles en 1769), volvió a visitar a su hermana María Carolina, y su estancia en las Dos Sicilias sirvió para estrechar más los lazos austro-napolitanos, y mantener en su puesto a Acton, cuya destitución fulminante exigía el inexorable Carlos III desde Madrid.

En febrero de 1784 llegó a la ciudad de Nápoles, como embajador de España, el asturiano vizconde de la Herrería, diplomático de dilatada carrera por las Cortes septentrionales, al que Floridablanca dio unas Instrucciones taxativas, que se reducían a conseguir la destitución de Acton al precio que fuera, subordinando a este objetivo todas las demás gestiones de su comisión diplomática.

¿ Y cuál fue el resultado de esta concentración artillera? Nulo. Acton continuó en su puesto, con mayor ascendiente si cabe que antes; el distanciamiento entre Carlos III 
y su hijo Fernando se ahondó más, y el achacoso vizconde hubo de salir de Nápoles con las orejas gachas, después de una misión fallida, que apenas había durado un año.

Peor fortuna le cupo, si es posible, a su sucesor Simón de las Casas, que llegó a la embajada de Nápoles en marzo de 1785, con iguales Instrucciones que Herrería, y en noviembre de ese mismo año, esto es, a los ocho meses de estancia, salió ocultamente de la ciudad, sin haber presentado siquiera sus credenciales en la Corte.

Empecemos por reconocer que las tretas empleadas por Casas, con mejor voluntad, qué duda cabe, para lograr la destitución de Acton, no fueron precisamente un modelo de alta diplomacia. A primeros de octubre de 1785, Casas tuvo en el sitio real de Portici un violento altercado con la reina María Carolina, que acusó al embajador español del crimen de querer "aperire glio occhi a suo Marito", el rey.

Según informaba el embajador Azara desde Roma: "Al día siguiente de esta marimorena, el general Acton descubrió que le habían robado de su papelera los documentos más importantes que ella guardaba. Nadie dudó del hurto, y como en toda Nápoles no hay más ladrones que Casas y (su secretario) Campos, éstos fueron los robadores, sin que hubiese la menor duda de ello. Se pidieron estos papeles a Casas cara a cara, y éste fue tan bribón que no los quiso devolver, y cara a cara fue amenazado por la reina di farli tirare una archibusciata, di farli dare veleno, e di bruciarli la casa... Creerá V.E. que escribo una novela. Nada menos que eso. No es ni la mitad de la verdad".

Dado el peligro real que corría, Casas escapó de Nápoles como un pícaro la madrugada del 26 de noviembre de 1785, con el cuerpo lleno del miedo que le produjo un atraco perpetrado en su casa por los esbirros de Acton y María Carolina.

Significativamente, en Madrid no rechistaron ante semejante atentado contra el Derecho de Gentes. Como única contrarréplica, Casas fue nombrado embajador en Venecia, con el mismo sueldo, sucediendo en la Dominante al interino Paco Moñino, el hermano de Floridablanca. En marzo de 1786 se cerró la embajada española de Nápoles, con la marcha del secretario Clemente Campos, y las relaciones hispanonapolitanas quedaron rotas hasta 1791, sin más representación oficial que la del cónsul español Antonio Marqués. Para entonces hacía ya tres años que Carlos III descansaba en el panteón real del Escorial.

Al contrario que Azara, el político Pizarro tenía a Casas por un "excelente diplomático", y puede que lo fuera en otras circunstancias más favorables. Esto no obstante, aunque la misión de Casas en Nápoles se vio viciada por una serie de torpezas personales, ajenas por completo a la finura del estilo diplomático, y difícilmente justificables, por buena que fuera su voluntad de servicio; esto no obstante -repito- sería injusto que Casas cargara, ante el tribunal de la Historia, con todos los vidrios rotos, porque a fin de cuentas, él no fue más que un criado fiel, a quien su amo le encomendó una tarea excesiva, por cuyo cumplimiento hizo Casas todo lo posible -e incluso lo imposible-, hasta el extremo de comprometer su honor, y sacrificar su dignidad personal.

Sin quitar, pues, una tilde a las torpezas diplomáticas del honrado Casas, la parte más injustificable de todo este lamentable asunto recae, sin género de duda, sobre Carlos III y su ministro Floridablanca, empecinados en conseguir un imposible. Esta ceguera celtibéricamente pertinaz, no sólo fue ridícula en sí misma, sino que afectó gravemente a todo el andamiaje de las relaciones hispano-napolitanas de finales del 
XVIII, pues suscitó unas situaciones más propias de la picaresca barriobajera del "vaudevil" barato, que de la diplomacia clásica, propiciando además el que una mujer fuera capaz de hacer saltar a dos embajadores de alto bordo.

Resumiendo lo expuesto, ¿qué se puede decir, como conclusión, no ya de la Política Exterior de Carlos III (autorizadamente expuesta por otros conferenciantes), sino de la diplomacia de Grimaldi y, sobre todo de Floridablanca, que fueron sus más destacados gestores?

Las terribles sátiras aparecidas en Madrid en 1788 acusaban descaradamente al murciano, en cuyas manos había dejado Carlos III, desde hacía tiempo, "el cuidado de todo el Estado español (como observaba el secretario de embajada austriaco José Thim), y le echaban en cara de una forma virulenta que, al frente de las embajadas españolas en el extranjero, no habían puesto más que a sacristanes y a chuchumecos que no pudieran hacerle sombra.

Tales acusaciones eran exageradas, y por lo mismo, distorsionaban la realidad, sin duda alguna, pero no se puede silenciar que, en lo concerniente a la Península Italiana, los embajadores españoles destinados allí fueron, en general, más o menos víctimas del tráfago que se traía entre manos el archiocupado Floridablanca, cuya poca videncia (y su marcada inclinación al favoritismo) a la hora de elegir sujetos idóneos, le hacen muy poco honor como estadista y hombre de gobierno.

Se dirá tal vez que Floridablanca, como cualquier otro ministro de Estado, no podía arar su parcela (que él procuraba agrandar apropiándose de otros ministerios, además de la Secretaría de Estado) más que "con los bueyes que tenía a mano". Pero esta paremia cazurra no deja otra salida que la de sospechar, que los diplomáticos españoles del siglo XVIII, sólo les iba bien cuando su misión era un rigodón festivo, pero que no eran muy duchos para actuar en unos países cuyas situaciones políticas conflictivas no les ponían fácil la tarea de negociar ventajosamente en favor de su patria. Personalmente me niego a aceptar en bloque este hecho, porque suscribirlo sería como cruzar el Rubicón.

Esto no obstante, en los corrillos y mentideros madrileños del XVIII se decía, citando al poeta Góngora (1561-1627), que los diplomáticos españoles de entonces, poco o mal respaldados por su Gobierno, "apenas si llegaban, cuando llegaban apenas'. Lo curioso es que el poeta cordobés estampó esta frase cuando los embajadores de España estaban, al parecer, respaldados por el formidable y poderoso Felipe II, en cuyos dominios - dicen- no se ponía el sol. 